\title{
Numerical Modelling of Y Joints of Trusses Made of Steel Hollow Sections
}

\author{
Srđan ŽIVKOVIĆ*, Nenad STOJKOVIĆ, Dragana TURNIĆ, Marko MILOŠEVIĆ
}

\begin{abstract}
The use of welded structural hollow sections in civil engineering is relatively new. Constructing and dimensioning joints of steel trusses made of welded structural hollow sections requires a more specified approach, compared to traditional joints, achieved by gusset plates. Stress and local deformations at the contact between elements are non-linear and very complex. In this paper, the FEM modelling of the Y-joint was performed, accounting for the non-linear behaviour of steel. The ultimate bearing capacities of the joint were determined numerically, by applying different failure criteria. The results showed very good agreement with the experimental data.
\end{abstract}

Keywords: hollow sections; steel modelling; steel trusses; $Y$ joints

\section{INTRODUCTION}

The use of hollow trusses for bearing steel constructions in civil engineering is relatively new. The production of hollow steel trusses with square or rectangular cross section begins in the second half of 20th century, in England (1959), by Stewart \& Lloyds and in Germany (1962) by Mannesmann, with reshaping circular seamless tubes while they are hot. At the approximately same time, square and rectangular hollow sections trusses have been produced using the cold procedure.

During the period between two World Wars, most of the hollow truss steel grid constructions were made using montage element joints, bolts/rivets and gusset plates. During the last 30 years, in industrially developed countries all over the world the ratio between working hour price and used materials price has grown, which led to producing less complex directly welded joints and exclusion of gusset plates and other additional elements.

Constructing and dimensioning joints of steel trusses made of welded structural hollow sections require a more specified approach, compared to traditional joints achieved by gusset plates. Stresses and deformation state of joints is very complex, which makes the analysis of behaviour of these joints under ultimate limit state and serviceability limit state of use by only analytical postulates complicated and inaccurate. Modelling the primary material-steel, presents a particular problem. The results based on the limit states theory show that behaviour of these joints at the state of fracture depends not only on geometrical characteristics of connected element and primary material quality, but also on configuration-the shape of joint and type and level of load in chords.

During last 40 years, a large number of both experimental and numerical investigations of the behaviour of joints made of RHS (rectangular hollow section) and CHS (circular hollow section) with various configurations, as well as the joints made of hollow profiles and $\mathrm{H}$-profiles have been performed. In [1] the authors performed the numerical investigation of stress concentration in various configurations of CHS to RHS Yjoints. The authors formulated the equations for determination of stress concentration factors for hot spot stresses by utilizing the results of FEM modelling. Wang et al. [2] performed non-linear FEM analysis for determination of ultimate loading capacity of cast tubular
Y-joints. They found it to be highly sensitive to the variations of the geometric parameters, namely the thickness and the diameter of the chord and the angle between the brace and the chord. In the case of welded joins, the FEM modelling is even more sensitive to the geometrical parameters. The existence of welds usually implies sharp transitions in the geometry, leading to high stress concentrations. In these cases, the accuracy of the calculation is highly dependent on the mesh strategy, especially on the element size. In [3], the authors analysed different mesh generation procedures with the aim of achieving the best results without significant increase of the computational cost. However, regardless of the applied mesh generation strategy, intensive mesh refinement is usually necessary for achieving adequate calculation results [4-7]. Another aspect that is of great importance for the FEM modelling is the choice of the material parameters. In order to reduce the calculation time, often a simplified rather than the exact stress-strain relationship is applied. Usually, bilinear model with isotropic hardening is applied for defining stress-strain relationship in FEM analysis. Some limitations of this type of material model are presented in [8].

The aim of this paper was to perform numerical (FEM) modelling of a truss joint made of hollow sections, keeping the model as simple as possible, while taking into consideration material nonlinearity. The modelling was performed using the commercial software package ANSYS, on the example of "Y" joint made of RHS profiles. For the purpose of validating numerical results, the data of the experimental testing of the same joint configuration were provided. The calibration of the developed model was performed by comparing the numerically and experimentally obtained loaddisplacement curves. The ultimate bearing capacities of the joint were determined numerically, by applying different deformation limit or the strain limit criteria.

\section{EXPERIMENTAL INVESTIGATION}

Experimental testing [9] was performed on Y-type joint made of quadratic hollow section cold formed S235JRH steel profiles. The geometry of the joint is shown in Fig. 1. The chord was made of RHS $80 \times 80 \times 3$ profile. The brace was made of RHS $50 \times 50 \times 4$ profile. The angle between the brace and the chord was $45^{\circ}$. The total length 
of the chord was $400 \mathrm{~mm}$ and the length of the brace at the crown toe side was $200 \mathrm{~mm}$. The two elements were welded and the thickness of the fillet weld was $3 \mathrm{~mm}$.

Three samples were tested quasi-statically. The test was aiming to determine the ultimate loading capacity of the joint according to the deformation limit criterion of reaching the local deformation of $3 \%$ of the chord width or height. The experimental setup is shown in Fig. 2. The chord was positioned inclined at an angle of 45 degrees from the horizontal plane, putting the brace in the vertical position. This allowed the application of the vertical load to the brace element. In order to avoid any load eccentricity, the load was applied through the sphere joint element placed between the hydraulic press and the brace. The load intensity was measured using a $50 \mathrm{kN}$ load cell, placed between the hydraulic press and the sphere joint (Fig. 2a). Simultaneously, the local deformations (displacements) were measured in three spots (Fig. 2b): at the crown toe side weld (in the middle of the chord top flange), and on the two side surfaces of the chord $(10 \mathrm{~mm}$ from the chord top surface). The displacements were measured using the HBM linear variable displacement transducer with the measuring range of $\pm 2 \mathrm{~mm}$. Thus, the largest value of the displacement was limited to $4 \mathrm{~mm}$. The data recording was performed using data acquisition system SPIDER8. The sampling frequency was $10 \mathrm{~Hz}$.

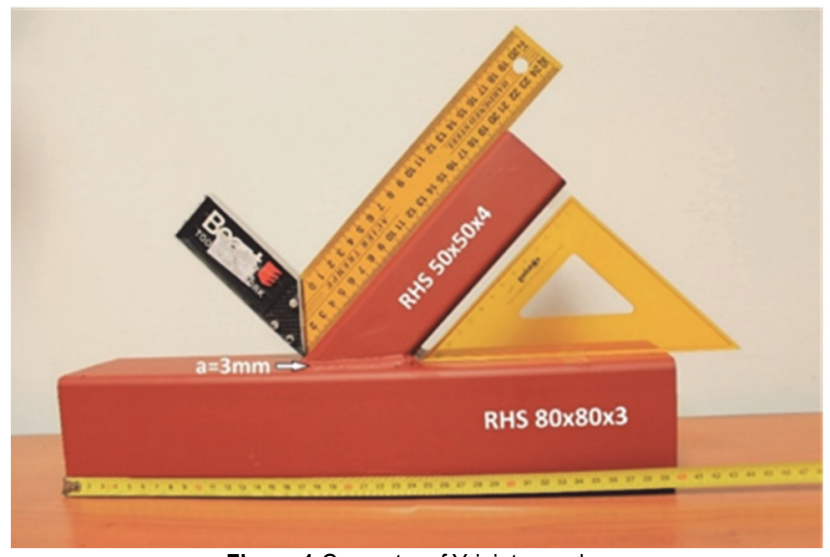

Figure 1 Geometry of Y-joint samples

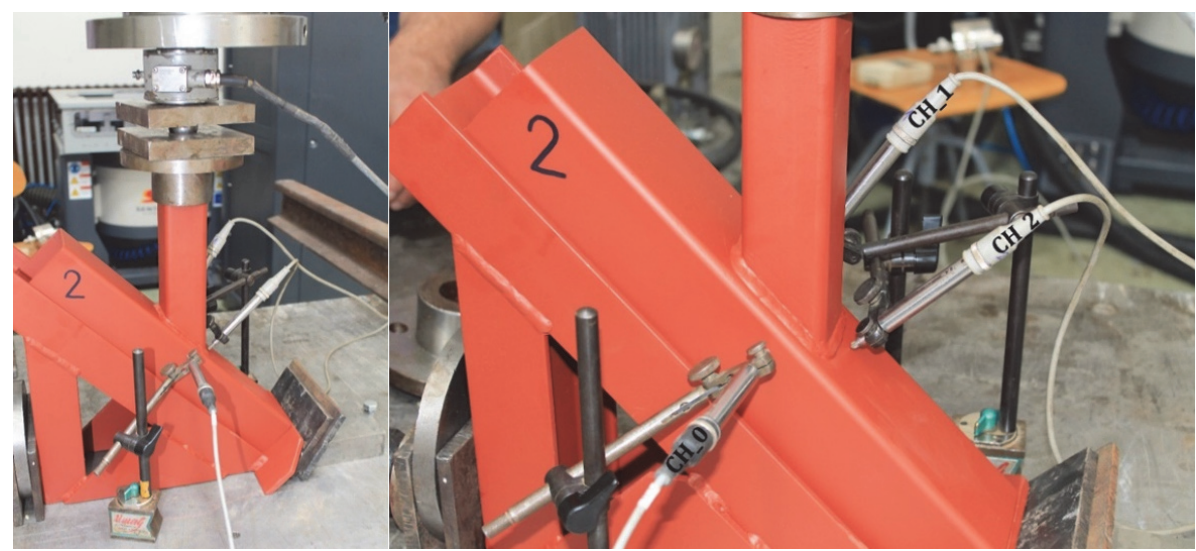

Figure 2 Experimental setup

\section{FEM MODELLING}

FEM modelling was performed using commercial software package ANSYS. In the analysis, material and geometrical nonlinearities were taken into consideration.

\subsection{Geometry and Boundary Conditions}

The joint was created as an assembly of two solid bodies. The first body consisted of the diagonal brace and the fillet weld, and the second one was the chord. For the purpose of simplicity, the weld was modelled only at the straight parts of the brace, excluding the parts at the curved edges. In order to accurately represent the loading conditions an additional solid body was created and aligned with the top surface of the brace. It simulated the sphere joint lower plate. The boundary conditions were defined in such a way that they represent the experimental conditions as accurate as possible, and given in Tab. 1 and Fig. 3. The contact between the brace/fillet weld and the chord, as well as the sphere joint plate and the upper head of the brace was created by defining a bonded contact pair between surface body faces.

\begin{tabular}{|c|c|c|}
\multicolumn{3}{|c}{ Table 1 Boundary conditions } \\
\hline $\begin{array}{c}\text { Notation } \\
\text { Fig. 3 }\end{array}$ & Type of element & $\begin{array}{c}\text { Fixed } \\
\text { displacements }\end{array}$ \\
\hline A & Surface & $Z=0$ \\
\hline B & Line & $X=Y=Z=0$ \\
\hline C & Surface & $Y=0$ \\
\hline D & $\begin{array}{c}\text { Line } \\
\text { (both sides of the chord) }\end{array}$ & $\begin{array}{c}X=0 \\
\text { E }\end{array}$ \\
\hline $\begin{array}{c}\text { Node } \\
\text { (middle of the top surface of the } \\
\text { solid plate) }\end{array}$ & $\begin{array}{c}\text { Load as nodal } \\
\text { displacement } \\
Y=Z=6 \text { mm }\end{array}$ \\
\hline
\end{tabular}

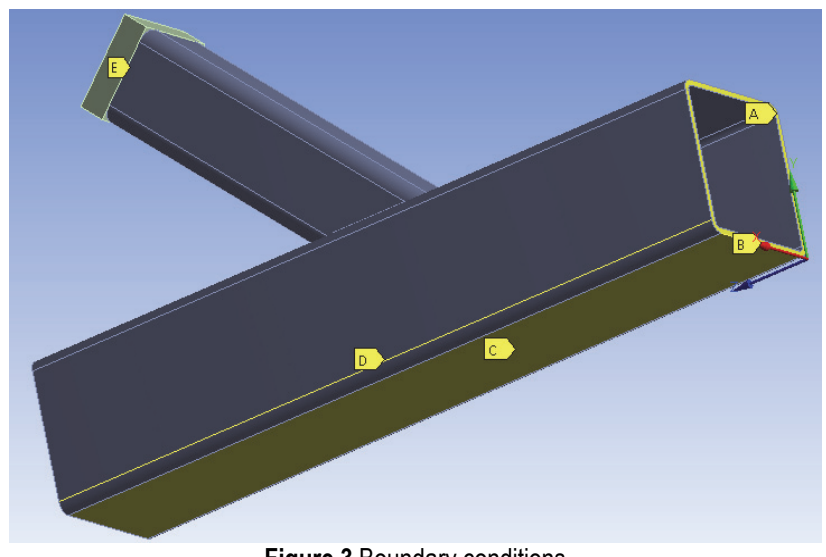

Figure 3 Boundary conditions 


\subsection{FE Mesh Generation}

The mesh was generated using the ANSYS Mechanical built in automatic mesh generator. The element size was controlled using the body sizing command. In the high stress zones, at the contact between brace and chord, automatic mesh refinement was performed on the surface level. It was set to one half of the body element size. In such a way, it was made easier to perform the mesh convergence study only by changing the element size on a body level. The results were calculated for the element size equal to 15,10 and $5 \mathrm{~mm}$. The meshing was performed using SOLID187 elements, a higher order 3-D, 10 - node element with a quadratic displacement behaviour, which is suited to modelling irregular meshes. The results of the mesh convergence study, depicted in Fig. 4 for the total strain development with the load increase, indicated that the calculations performed on the two finer meshed models gave no significant difference. Thus, both meshes could be considered as adequate. The mesh with the body level element size of $10 \mathrm{~mm}$ is shown in Fig. 5 .

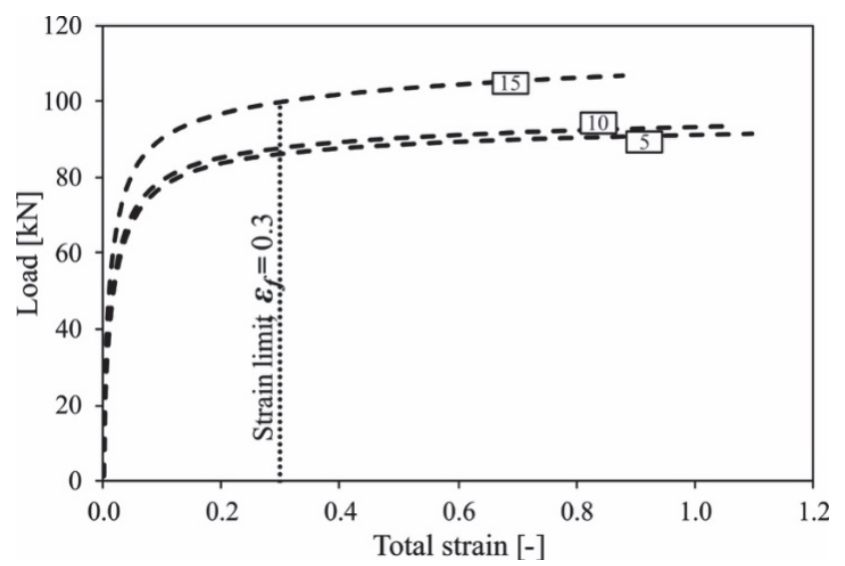

Figure 4 Mesh convergence study

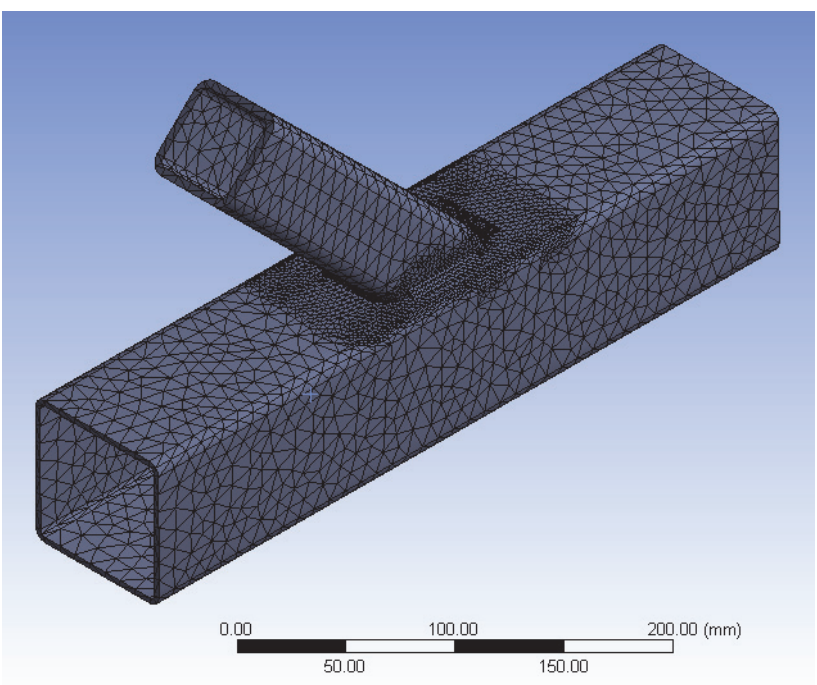

Figure 5 FE mesh of the SHS Y-joint model

\subsection{Material Parameters}

The choice of the material model corresponded to the type of the analyses that were performed. The linear elastic material model is appropriate for analysing behaviour of the joints within elastic region, up to determining the load at which the first plastic strains occur. Since most of the analyses included the plasticity, beside the elastic modulus and Poisson's ratio, the input of true stress-true strain data was required. The use of bilinear material model has the advantage of reducing computational time, compared to more complex models. However, this type of model is not suitable for predicting the ultimate load capacity since it can result in stresses much higher than the value of ultimate strength of material [8]. In this study, the non-linear behaviour of the steel was modelled applying multilinear isotropic hardening. The material parameters were taken from the experimental results published in [10]. The values were taken from those tests that were performed on the same thickness of the element and the closest dimensions to the elements of the present study. The typical stressstrain curve of cold formed steel S235JRH, obtained by testing coupons from HS profiles is shown in Fig. 6. Although the provided experimental data showed slight difference between the results obtained by testing flat and corner coupons, herein the material parameters for each section were considered as uniform and are given in Tab. 2. The slope of the stress-strain curve between the yield strength $\left(f_{y}\right)$ and ultimate strength $\left(f_{u}\right)$ is taken as $1 \%$ of the Young's modulus $(E)$. After reaching the ultimate strength, the material was considered to be perfectly plastic. The weld material was modelled using the same parameters as the material of the brace element. The observed maximum strain at failure $\left(\varepsilon_{f}\right)$ varied more than other parameters, but could be considered to be around 0.3 .

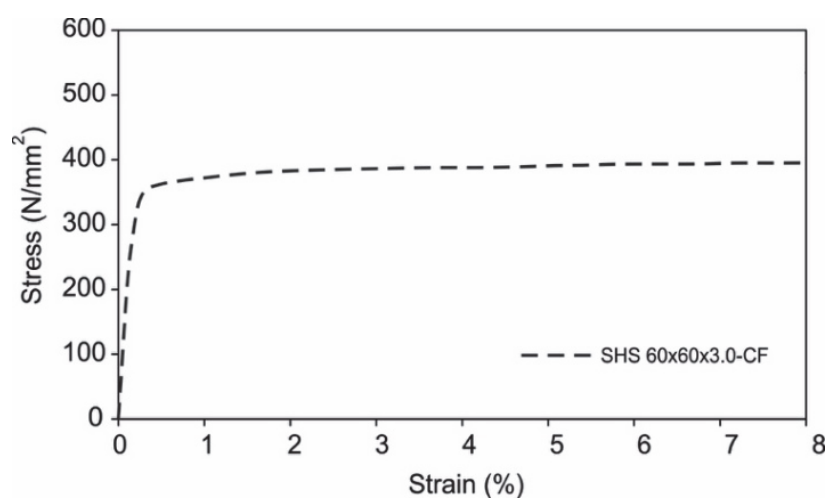

Figure 6 Typical stress-strain curve from cold formed tensile coupons (SHS 60 $\times 60 \times 3.0)[10]$

Table 2 The material parameters used in FEM modelling

\begin{tabular}{|c|c|c|c|}
\hline element & $E / \mathrm{MPa}$ & $f_{y} / \mathrm{MPa}$ & $f_{u} / \mathrm{MPa}$ \\
\hline SHS $50 \times 50 \times 4$ & 201600 & 410 & 430 \\
\hline SHS $80 \times 80 \times 3$ & 207400 & 361 & 402 \\
\hline
\end{tabular}

\subsection{Analysis Setup}

The static structural type of analysis was performed for different cases of loading. For determination of the ultimate bearing capacity of the joint, a nodal displacement was applied to the central node of the sphere joint plate, in the brace axis direction. For this reason, in order to simulate a rigid body, the material of this plate was modelled using 1000 times higher values of Young's modulus and material strength. Further, in order to compare the experimentally and numerically obtained deformations at the characteristic load intensities, additional analyses were performed by applying the nodal force to the centre of the plate. Application of the 
displacement was performed in 10 steps, whereby the first 5 steps were significantly smaller than the last ones. This was calibrated in such a way that load displacement curve shows smooth transition from linear to non-linear region. In later stage, when the plastic behaviour becomes dominant, even with the larger steps the smoothness of the curve is not harmed. In the cases where nodal force was applied to the centre of the plate the analyses were performed in one step, with default substep settings.

\section{RESULTS AND DISCUSSION}

In the first part of this research, during the mesh convergence analysis, it was noticed that the von-Mises stress values in the stress concentration regions significantly exceeded the ultimate strength of the material (Fig. 7). This problem was not solved even with the decrease of the mesh size. Since the modelling of the material plastic behaviour included the plateau after reaching the ultimate strength, it was believed by the authors that the reason for this problem lies in the computational procedures of the FEM modelling. Namely, the extrapolation of the solution results from the integration points to the nodes is accurate only in the elastic regions. When the plasticity is involved, this could lead to inaccurate results, since the linear extrapolation does not follow the material behaviour within one element. Error could be reduced by decreasing the element size, i.e. reducing the distance between integration points and nodes. The extrapolation could be also controlled using ERESX command [11], applied through the ANSYS APDL-snippet. In this way, it could be specified whether the results would be extrapolated or copied from integration points to nodes. Fig. 7 shows the von-Mises stress distribution with allowed extrapolation, at the stage at which a large part of the chord top side was in the plastic region. An unrealistic increase of the stresses, far beyond the ultimate stress, could be clearly seen at the transition from elastic to plastic region. Reduction of the element size could result in obtaining more realistic stresses, since it decreases the difference between the extrapolated value and the value at the integration point. However, in order to "catch" the spreading of the yielded zone, a very fine mesh in a relatively large zone is required. Another solution is to disable the extrapolation or enable it partially. In the first case, the values are copied from the integration points to nodes. The second case involves extrapolation only in elements which have not yielded. However, in this case, the occurrence of the stresses above the ultimate strength is observed as well. The final calculations, as well as the mesh convergence study (Fig. 4), were performed with extrapolation totally disabled.

The calibration of the model was performed by comparing the numerically obtained load-displacement curve with the experimental one. As mentioned above, the nodal displacement boundary condition of $8.485 \mathrm{~mm}(6$ $\mathrm{mm}$ in $Y$ and $Z$ direction) was gradually applied at the centre node of the rigid plate (10 steps of $1 \mathrm{~s})$. The loaddisplacement curve is shown in Fig. 8. It represents the displacement parallel to the $Y$ axis of the node distanced 5 $\mathrm{mm}$ from the crown toe fillet weld (the measurement point shown in Fig. 2). On the FEM curve, the point marked with the arrow corresponds to the load and displacement at the moment when the limit strain (0.3) was reached. By analysing the results, it was concluded that this happened a little bit before the time step of $7.9125 \mathrm{~s}$ (Fig. 9), at which the total nodal displacement of the loading plate was 2.7 $\mathrm{mm}$. This point is considered as a moment of the beginning of failure, and the corresponding load is the ultimate capacity of the joint. The bearing capacity obtained in this way was $87.92 \mathrm{kN}$. In Fig. 10, the corresponding vonMises stresses are shown.

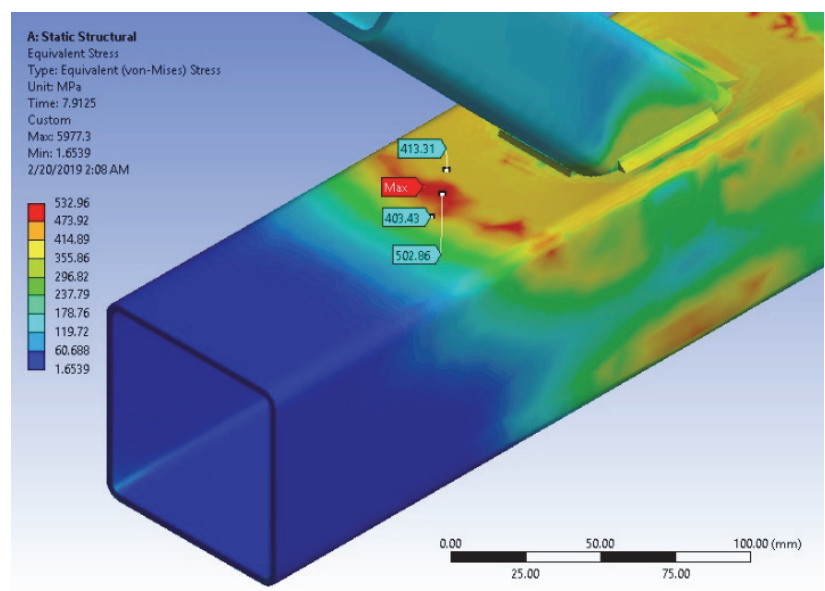

Figure 7 The stress distribution with extrapolation enabled (default settings)

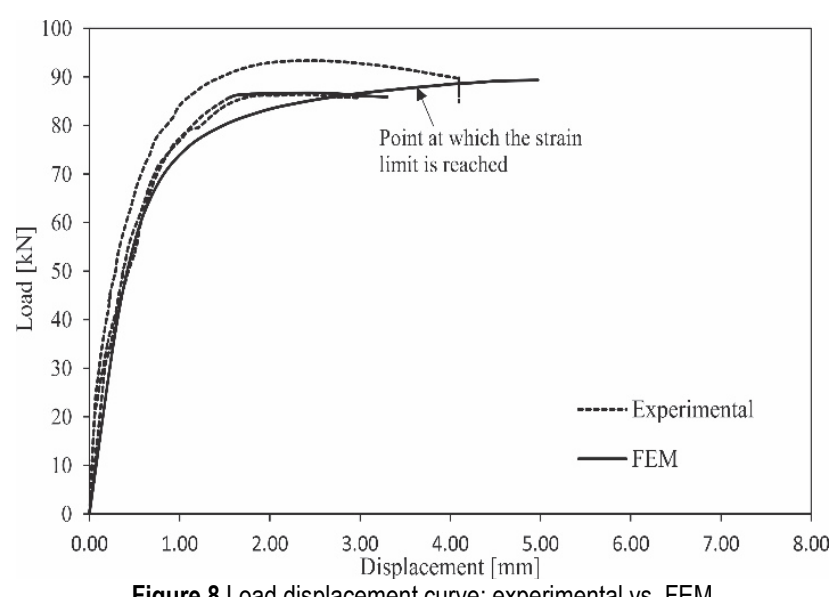

Figure 8 Load displacement curve: experimental vs. FEM

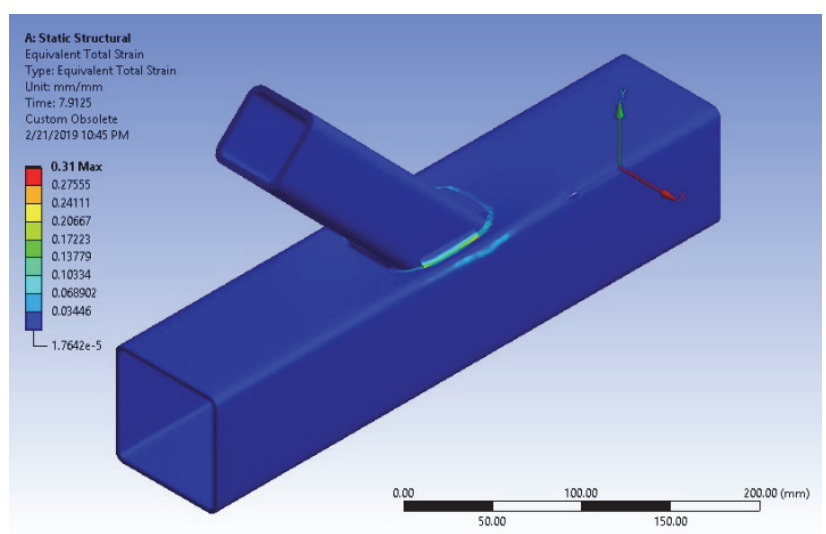

Figure 9 Equivalent total strain at the time parameter equal to 7.9125

Further analyses were focused on the local deformation of the chord top flange at the specific values of loading. Many studies have shown that the exhaustion of bearing capacity of many different types of SHS joints is a direct result of the local plastification of the chord at and around the contact with the brace $[12,13]$. 
Consequently, the failure criteria are mostly based on the chord local deformation. The International Institute of Welding adopted the deformation limit of $3 \%$, which corresponds to the ultimate bearing capacity of the joint [12]. For the chord that was analysed in this research, the limit deformation calculated in this way is $2.4 \mathrm{~mm}$. Many of the recent researches on the bearing capacity of this type of joints were based on the application of the local deformation limit criteria [4, 6, 14]. Herein the local deformation was calculated for two different load levels. The first is determined as the ultimate bearing capacity of the joint using the Yield line method. In principle, in this method various yield line patterns have to be examined in order to obtain the lowest capacity. More details about the analysis procedure and the corresponding equations could be found in reference [15]. This model neglects the thickness of the chord flange as well as the thickness of the fillet welds. The second one, developed and presented in detail in [9], based on the yield line analysis principle as well, takes into account the thicknesses of the chord flange and weld. Calculation results are given in Tab. 3 .

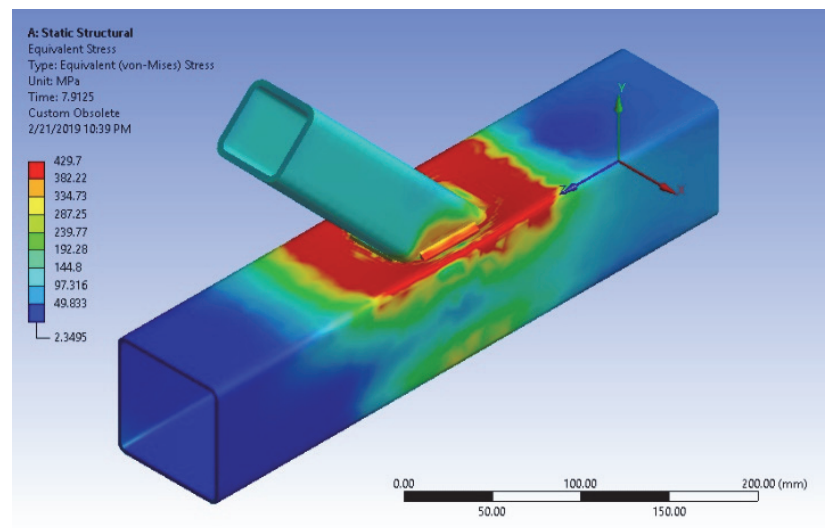

Figure 10 Von-Mises stress distribution at the time of reaching strain limit

\begin{tabular}{|c|c|c|c|}
\hline $\begin{array}{l}\text { Procedure of determination of ultimate bearing } \\
\text { capacity }\end{array}$ & $\begin{array}{c}\text { Applied nodal load } \\
\text { (calculated Ultimate } \\
\text { bearing capacity) } \\
\text { / kN }\end{array}$ & $\begin{array}{c}\text { Max local deformation - } \\
\text { FEM } \\
/ \mathrm{mm}\end{array}$ & $\begin{array}{c}\text { Max local } \\
\text { deformation-experimental } \\
/ \mathrm{mm}\end{array}$ \\
\hline $\begin{array}{l}\text { Yield line analysis with weld and flange thicknesses } \\
\text { neglected }\end{array}$ & 35.32 & 0.249 & 0.22 \\
\hline $\begin{array}{l}\text { Yield line analysis with the weld and flange } \\
\text { thicknesses included in the analysis }\end{array}$ & 69.52 & 0.786 & 0.72 \\
\hline Experimentally determined & 88.81 & $\begin{array}{l}3.6 \text { (point of reaching the } \\
\text { strain limit of } 0.3 \text { ) }\end{array}$ & 2.47 \\
\hline
\end{tabular}

From the results of non-linear FEM analysis, given in Tab. 3, it could be concluded that the calculated deformation is in very good agreement with the experimentally obtained values for both loading levels. For the load calculated at the moment of reaching the peak strain equal to the maximum strain at failure, the displacement is higher than experimental. However, if the criterion of reaching local displacement of $2.4 \mathrm{~mm}$ is applied, the corresponding ultimate bearing capacity is equal to $84.4 \mathrm{kN}$ (Fig. 8), and in very good agreement with the experimentally obtained value.

Analysing both experimental and numerical results, it is evident that the failure occurs due to the plastification of the chord top flange. The bearing capacity, calculated by applying Yield line analysis, corresponds to the local deformation of $2.5 \%$. It is 2.5 times smaller than the experimental value. If the thicknesses of the flange and fillet weld are taken into account, this ratio decreases to 1.25. The FEM analysis, based the limit displacement, showed a much better agreement (the ratio was equal to 1.05). However, the application of limit strain criterion gave the value of ultimate bearing capacity closest to the experimentally obtained one.

\section{CONCLUSION}

This paper presented the results of numerical modelling of RHS Y-joint. The calculation results were validated using the experimental data. Ultimate bearing capacities were calculated by applying different failure criteria. The behaviour of the joint, observed within the experimental investigation, was very well represented by the results of the numerical analysis. The ultimate bearing capacities, calculated by the standard analytical procedures, giving the values equal to around $40 \%$ and $80 \%$ of the experimentally obtained ones, were conservative and on the safe side. This conservativity can be considered as a disadvantage from the economical point of view. The application of non-linear FEM analysis could be a remedy for this problem. It resulted in much better predictions of the failure load. In this paper it was shown that even with the relatively course mesh, the results could be very satisfactory.

\section{REFERENCES}

[1] Yin, Y., Liu, X., Lei, P., \& Zhou, L. (2018). Stress concentration factor for tubular CHS-to-RHS Y-joints under axial loads Local stress HSS Brace wall. Journal of Constructional Steel Research, 148; 768-78. https://doi.org/10.1016/j.jcsr.2018.06.003

[2] Wang, Y. Q., Jiang, Y., Shi, Y. J., \& Sun, P. (2008). Nonlinear analysis of ultimate loading capacity of cast tubular Yjoints under axial loading. Tubul. Struct. XII Proc. 12th Int. Symp. Tubul. Struct., 529-32. https://doi.org/10.1201/9780203882818.ch60

[3] Lie, S. T., Lee, C. K., \& Wong, S. M. (2003). Model and mesh generation of cracked tubular Y-joints. Engineering Fracture Mechanics, 70; 2003, 161-84. https://doi.org/10.1016/S0013-7944(02)00036-X

[4] Li, T., Lie, S. T., \& Shao, Y. B. (2018). Plastic collapse load prediction of cracked circular hollow section $\mathrm{T} / \mathrm{Y}$-joints under in-plane and out-of-plane bending. Ocean Engineering, 148, 136-48. https://doi.org/10.1016/j.oceaneng.2017.11.033

[5] Tousignant, K. \& Packer, J.A. (2018). Fillet weld effective lengths in CHS X-connections. II: Finite element modelling, 
parametric study and design. Journal of Constructional Steel Research, 141, 77-90. https://doi.org/10.1016/j.jcsr.2017.11.002

[6] Bittencourt, M. C., Lima, L. R. O. De, Vellasco, P. C. G. S., Silva, J. G. S., \& Neves, L. F. C. (2007). A Numerical Analysis of Tubular Joints under Static Loading.

[7] Lee, M. M. K. (1999). Strength, stress and fracture analyses of offshore tubular joints using finite elements. Journal of Constructional Steel Research, 51, 265-86. https://doi.org/10.1016/S0143-974X(99)00025-5

[8] Pelletier, H., Krier, J., Cornet, A., \& Mille, P. (2000). Limits of using bilinear stress-strain curve for finite element modeling of nanoindentation response on bulk materials. Thin Solid Films, 379; 147-55. https://doi.org/10.1016/S0040-6090(00)01559-5

[9] Živković, S. (2015). Contribution to the calculation of directly-welded connections in truss elements with hollow steel rectangular and square profiles, in Serbian. $\mathrm{PhD}$ Thesis, Ph.D. thesis,. University of Niš.

[10] Gardner, L., Saari, N., \& Wang, F. (2010). Comparative experimental study of hot-rolled and cold-formed rectangular hollow sections. Thin-Walled Structures, 48, 495-507. https://doi.org/10.1016/j.tws.2010.02.003

[11] ANSYS User's Manual, Swanson Analysis System Inc., 2017. n.d.

[12] Packer, J. A., Wardenier, J., Kurobane, Y., Dutta, D., \& Yeomans, N. (1992). Design Guide for Rectangular Hollow Section (RHS) Joints Under Predominantly Static Loading. International Committee for the Study and Development of Tubular Structures,Köln.

[13] Lan, X., Chan, T. M., \& Young, B. (2018). Structural behaviour and design of chord plastification in high strength steel CHS X-joints. Construction and Building Materials, 191, 1252-67. https://doi.org/10.1016/j.conbuildmat.2018.10.065

[14] Lan, X., \& Chan, T. M. (2019). Recent research advances of high strength steel welded hollow section joints. Structures, 17, 58-65. https://doi.org/10.1016/j.istruc.2018.11.015

[15] Wardenier, J, Packer, J, Zhao, X. L., \& Vegte, G. (2010). Hollow sections in structural applications, CIDECT, Geneva, Switzerland, 104.

\section{Contact information}

Srđan ŽlVKOVIĆ, assistant professor, PhD

(Corresponding author)

Faculty of Civil Engineering and Architecture-University of Niš,

Aleksandra Medvedeva 14, Niš, Serbia

E-mail: srdjan.zivkovic@gaf.ni.ac.rs

Nenad STOJKOVIĆ, senior lecturer, PhD

College of Applied Technical Sciences Niš,

Aleksandra Medvedeva 20, Niš, Serbia

E-mail:svnenad@yahoo.com

Dragana TURNIĆ, assistant professor, $\mathrm{PhD}$

Faculty of Civil Engineering and Architecture-University of Niš

Aleksandra Medvedeva 14, Niš, Serbia

E-mail: draganaturnic@yahoo.com

Marko MILOŠEVIĆ, Master in Civil Engineering, PhD student Innovation Center University of Niš, Faculty of Civil Engineering and Architecture-University of Niš,

Univerzitetskitrg 2, Niš, Serbia

E-Mail: marko.milosevic@gaf.ni.ac.rs 